Supplementary data for the article: P.M. Batinić, V.B. Đorđević, S.I. Stevanović, B.D. Balanč, S.B. Marković, N.D. Luković, D.Ž. Mijin, B.M. Bugarski, Formulation and characterization of novel liposomes containing histidine for encapsulation of a poorly soluble vitamin, Journal of Drug Delivery Science and Technology, 2020, 59, 101920, doi:

https://doi.org/10.1016/j.jddst.2020.101920

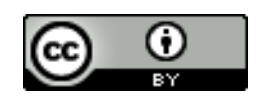

This work is licensed under the

Creative Commons - Attribution 4.0 International (CC BY 4.0) license 


\section{Formulation and characterization of novel liposomes containing histidine for encapsulation of a poorly soluble vitamin}

Petar M. Batinić ${ }^{1}$, Verica B. Đorđevićc ${ }^{2}$, Sanja I. Stevanović ${ }^{3}$, Bojana D. Balanč $\check{c}^{1}$, Smilja B. Markovićc ${ }^{4}$ Nevena D. Luković ${ }^{2}$, Dušan Ž. Mijin ${ }^{2, *}$, Branko M. Bugarski²

${ }^{1}$ Innovation Center of Faculty of Technology and Metallurgy, University of Belgrade, Karnegijeva 4, 11000 Belgrade, Serbia

2Faculty of Technology and Metallurgy, University of Belgrade, Karnegijeva 4, 11000 Belgrade, Serbia

3Institute of Chemistry, Technology and Metallurgy, Department of Electrochemistry, University of Belgrade, Njegoševa 12, 11000 Belgrade, Serbia

${ }^{4}$ Institute of Technical Science of SASA, Knez Mihailova 35/IV, 11000 Belgrade, Serbia

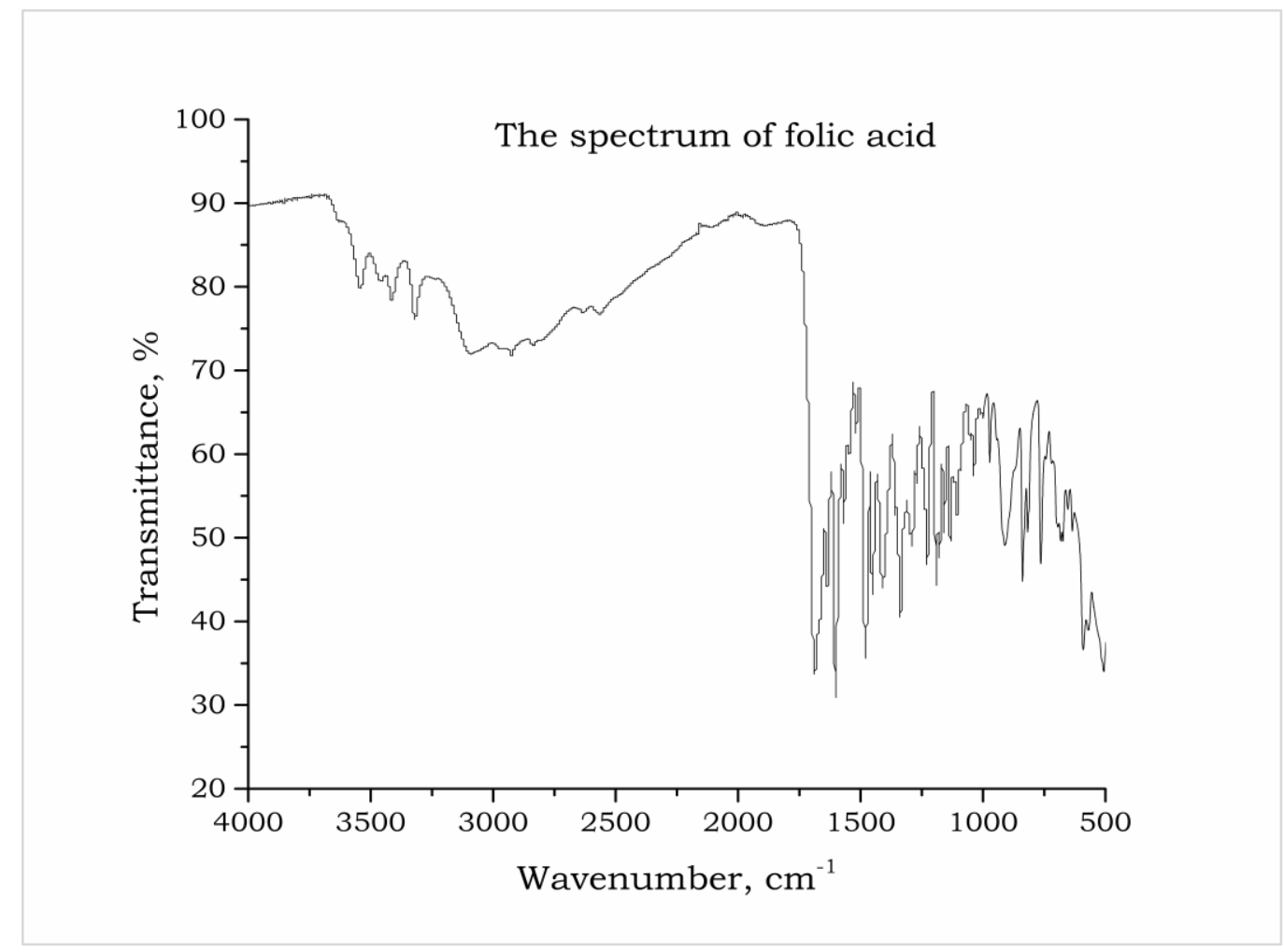

Figure S1. The spectrum of folic acid

凶* Corresponding author: D. Ž. Mijin (kavur@tmf.bg.ac.rs), (tel: +381113303671, fax: $+381113370387)$ 


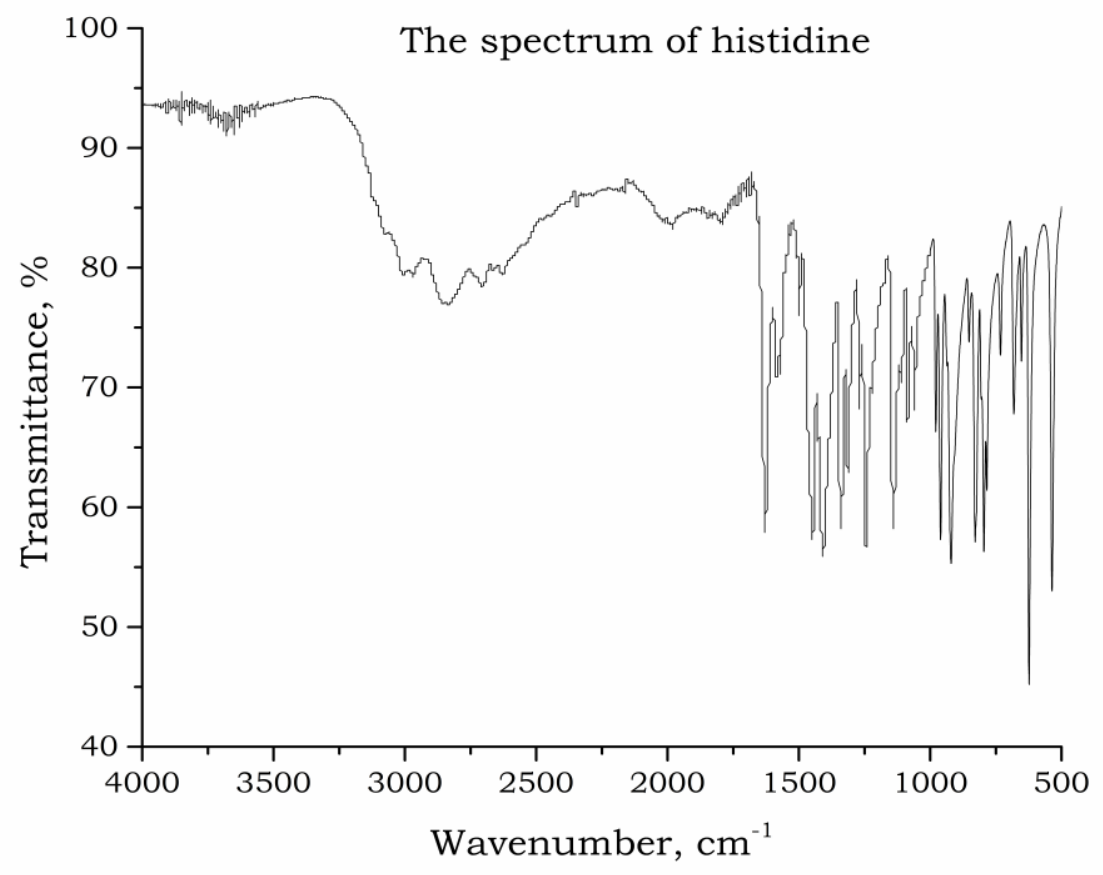

Figure S2. The spectrum of histidine

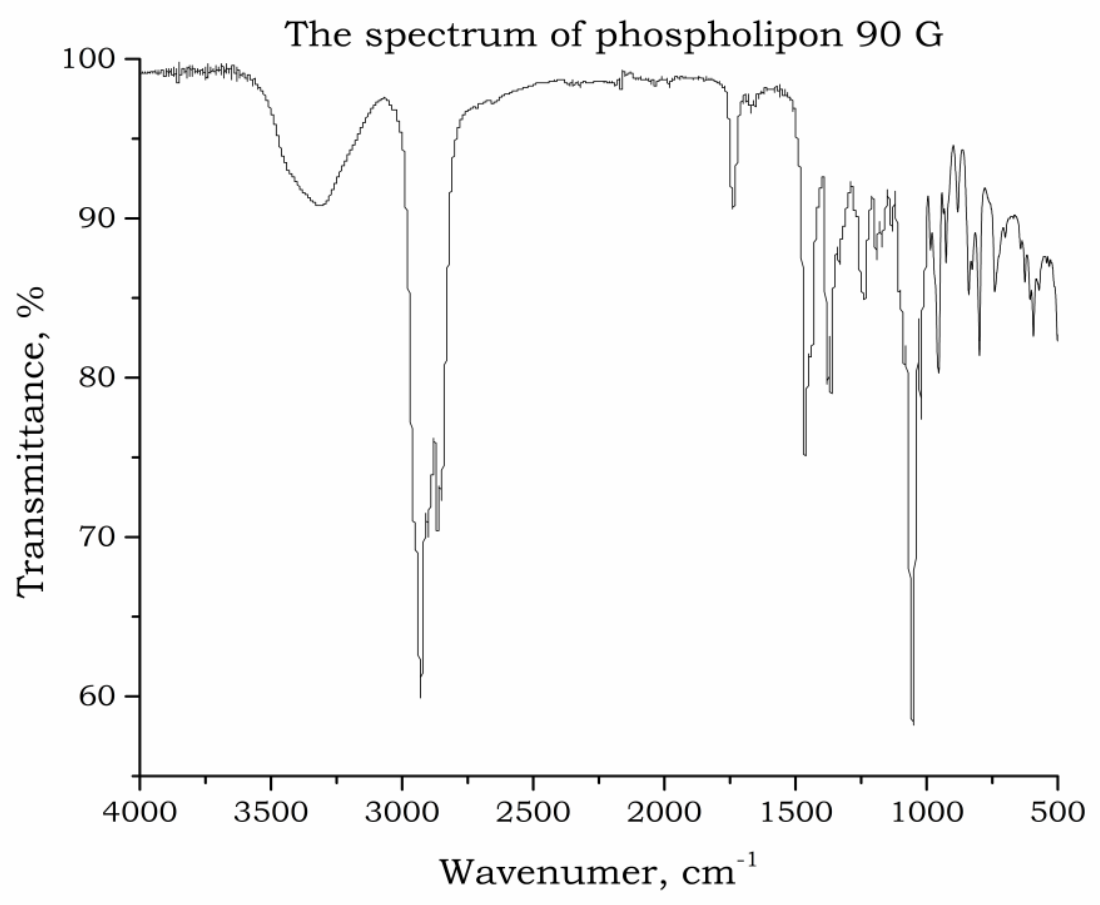

Figure S3. The spectrum of phospholipon $90 \mathrm{G}$ 


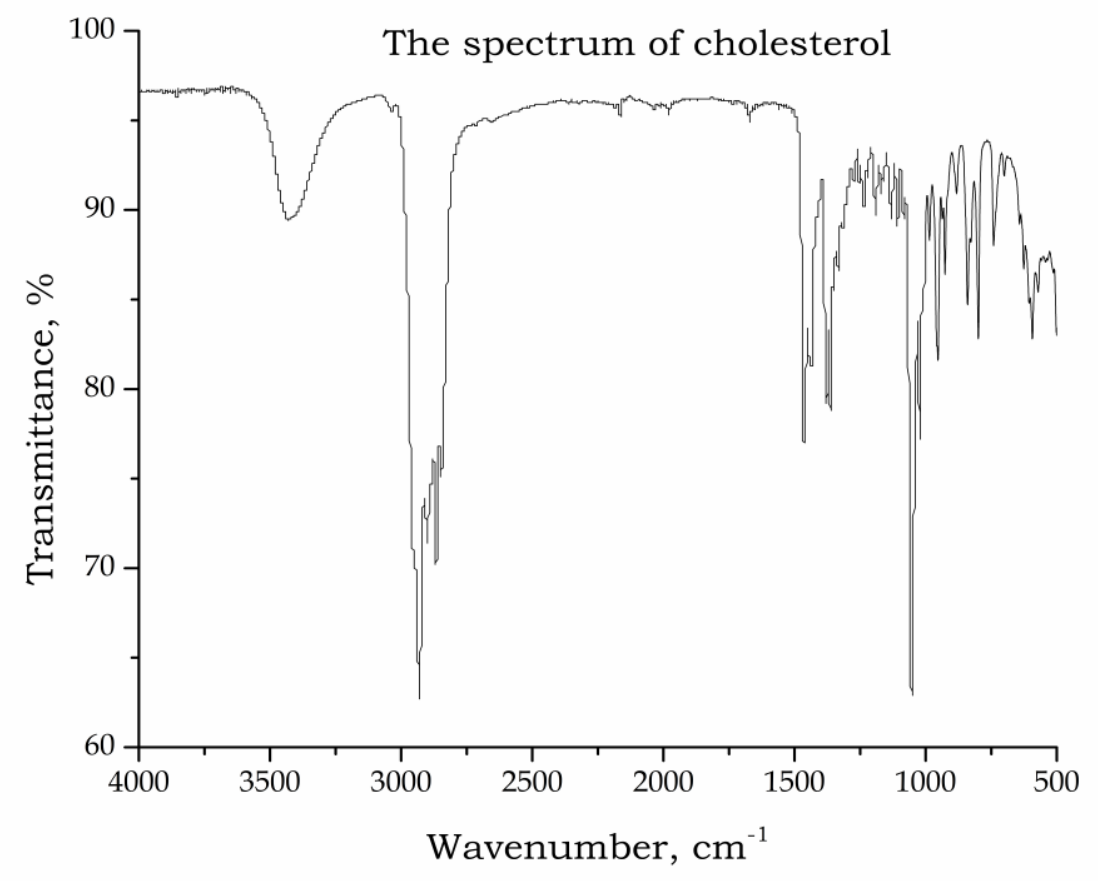

Figure S4. The spectrum of cholesterol

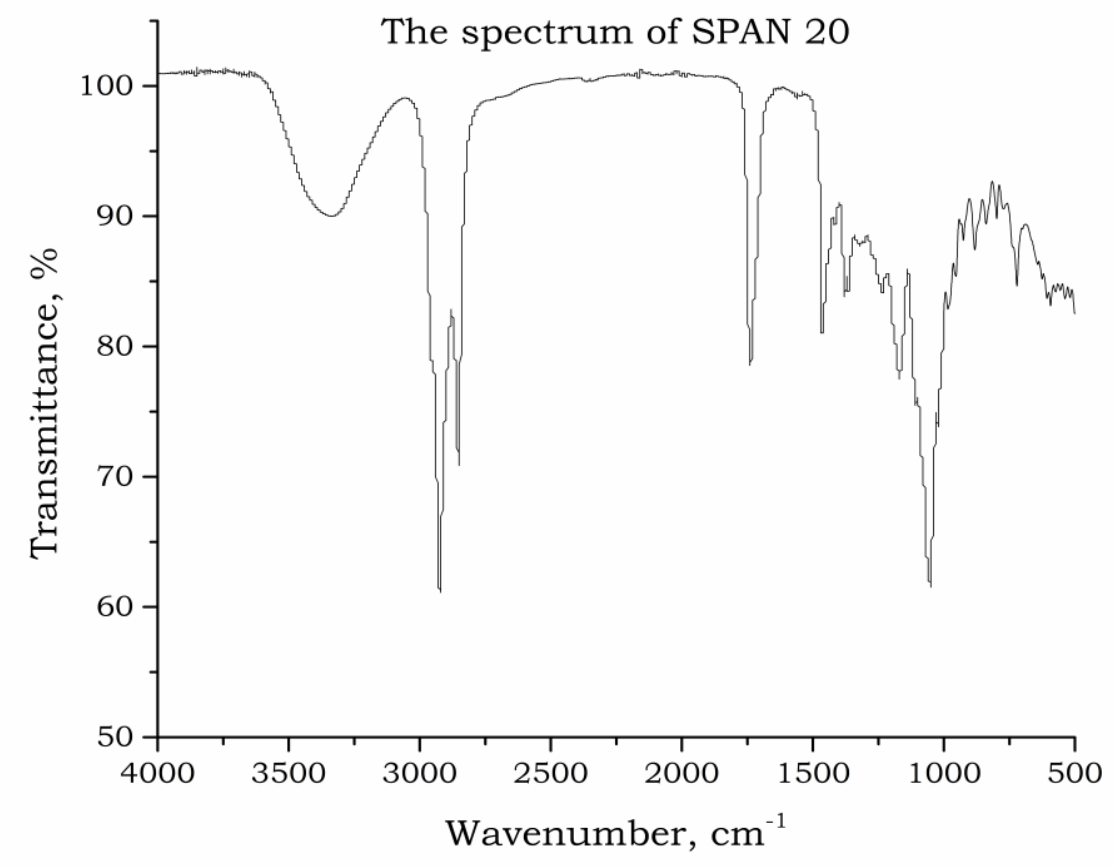

Figure S5. The spectrum of SPAN 20 